\title{
MESSAGE FROM THE CEO
}

\section{A warm welcome to the 2019 Annual Patient Safety Forum.}

In its ninth year, the forum is taking its quality and safety improvement journey to a new level and a new destination, the Western Region of Saudi Arabia.

In addition to the robust scientific program and the interactive educational experiences, the quality improvement researches, projects and stories are a remarkable source of learning.

It is truly inspiring to witness the large numbers of abstracts highlighting different aspects from patient safety research and improvement initiatives. This is a clear indication of the passion and enthusiasm among healthcare workers to improve quality and patient safety across the nation.

This is coupled with a rigorous peer-review process to ensure consistent evaluation and inclusion of high- quality projects.

On behalf of the MNG-HA staff and the teams who worked diligently to make the Forum a great success, I would like to thank all of the abstracts authors and welcome all participants and attendees and wish you all a productive and an inspiring experience.

\section{Bandar Al Knawy, MD, FRCPC}

Chief Executive Officer,

Ministry of National Guard -Health Affairs President,

King Saud bin Abdulaziz University for Health Sciences President,

Patient Safety Forum 2019 